Article

\title{
Maximizing Anhydrosugar Production from Fast Pyrolysis of Eucalyptus Using Sulfuric Acid as an Ash Catalyst Inhibitor
}

\author{
Dongyan Zhang 1,2,3,4 , Yuyang Fan 2,3,4,5, Anqing Zheng ${ }^{2,3,4, *}$, Zengli Zhao ${ }^{2,3,4}$, \\ Fengyun Wang ${ }^{1, *}$ and Haibin $\mathrm{Li}^{2,3,4}$ \\ 1 School of Chemical Engineering, Nanjing University of Science \& Technology, Nanjing 210094, China; \\ zhangdy@ms.giec.ac.cn \\ 2 Guangzhou Institute of Energy Conversion, Chinese Academy of Sciences, Guangzhou 510640, China; \\ fanyy@ms.giec.ac.cn (Y.F.); zhaozl@ms.giec.ac.cn (Z.Z.); lihb@ms.giec.ac.cn (H.L.) \\ 3 CAS Key Laboratory of Renewable Energy, Guangzhou 510640, China \\ 4 Guangdong Key Laboratory of New and Renewable Energy Research and Development, \\ Guangzhou 510640, China \\ 5 Clean Energy Key Laboratory of Liaoning, Shenyang Aerospace University, Shenyang 110136, China \\ * Correspondence: zhengaq@ms.giec.ac.cn (A.Z.); wangfy@njust.edu.cn (F.W.); \\ Tel.: +86-020-8705-7716 (A.Z.); Fax: +86-020-8705-7737 (A.Z.)
}

Received: 24 October 2018; Accepted: 29 November 2018; Published: 3 December 2018

\begin{abstract}
Anhydrosugars, such as levoglucosan (LG), are high value-added chemicals which are mainly derived from fast pyrolysis of pure cellulose. However, fast pyrolysis of raw lignocellulosic biomass usually produces a very low amount of levoglucosan, since alkali and alkaline earth metals (AAEM) present in the ash can serve as the catalysts to inhibit the formation of levoglucosan through accelerating the pyranose ring-opening reactions. In this study, eucalyptus was impregnated with $\mathrm{H}_{2} \mathrm{SO}_{4}$ solutions with varying concentrations (0.25-1.25\%). The characteristics of ash derived from raw and $\mathrm{H}_{2} \mathrm{SO}_{4}$-impregnated eucalyptus were characterized by $X$-ray fluorescence spectroscopy (XRF) and X-ray diffraction (XRD). The pyrolysis behaviors of raw and $\mathrm{H}_{2} \mathrm{SO}_{4}$-impregnated eucalyptus were performed on the thermogravimetric analysis (TGA) and pyrolysis-gas chromatography/mass spectrometry (Py-GC/MS). TG analysis demonstrated that the $\mathrm{H}_{2} \mathrm{SO}_{4}$-impregnated eucalyptus produced less char than raw eucalyptus. Py-GC/MS analysis showed that even small amounts of $\mathrm{H}_{2} \mathrm{SO}_{4}$ can obviously improve the production of anhydrosugars and phenols and suppressed the formation of carboxylic acids, aldehydes, and ketones from fast pyrolysis of eucalyptus. The rank order of levoglucosan yield from raw and impregnated eucalyptus was raw $<1.25 \% \mathrm{H}_{2} \mathrm{SO}_{4}<1 \%$ $\mathrm{H}_{2} \mathrm{SO}_{4}<0.75 \% \mathrm{H}_{2} \mathrm{SO}_{4}<0.25 \% \mathrm{H}_{2} \mathrm{SO}_{4}<0.5 \% \mathrm{H}_{2} \mathrm{SO}_{4}$. The maximum yield of levoglucosan $(21.3 \%)$ was obtained by fast pyrolysis of eucalyptus impregnated with $0.5 \% \mathrm{H}_{2} \mathrm{SO}_{4}$, which was close to its theoretical yield based on the cellulose content. The results could be ascribed to that $\mathrm{H}_{2} \mathrm{SO}_{4}$ can react with AAEM (e.g., $\mathrm{Na}, \mathrm{K}, \mathrm{Ca}$, and $\mathrm{Mg}$ ) and lignin to form lignosulfonate, thus acting as an inhibitor to suppress the catalytic effects of AAEM during fast pyrolysis of eucalyptus.
\end{abstract}

Keywords: eucalyptus; fast pyrolysis; acid impregnation; $\mathrm{H}_{2} \mathrm{SO}_{4}$; inhibitor; anhydrosugar

\section{Introduction}

The growing consumption of fossil fuels and the resulting environmental issues demand renewable resources to partly replace fossil fuels for the production of power, heat, liquid fuels, and chemicals [1-4]. Lignocellulosic biomass, as the only renewable carbonaceous resource, is being studied worldwide for the production of liquid fuels and chemicals from both academia and industry. 
Technologies for using biomass to produce liquid fuels and chemicals include pyrolysis, gasification, fermentation, catalytic conversion, and their hybrid processes [5]. One of the most promising technologies is fast pyrolysis due to its highest yield of pyrolysis liquid and lowest production cost [6-8]. Fast pyrolysis of biomass usually requires middle temperatures $\left(400-600{ }^{\circ} \mathrm{C}\right)$, a high heating rate $\left(>1000^{\circ} \mathrm{C} / \mathrm{s}\right)$, short vapor residence time $(<2 \mathrm{~s})$, inert atmosphere, and rapid quenching of the pyrolysis vapors, forming three fractions: char, permanent gas, and bio-oil [9-11]. The objective of fast pyrolysis is to minimize secondary reactions such as cracking, condensation, and polymerization for maximizing the yield of bio-oil. The yield of bio-oil can reach up to $50-75 \mathrm{wt} \%$ on a dry basis, depending upon biomass species and operating conditions. Bio-oil mainly comprises of water and hundreds of organic oxygenates, such as anhydrosugars, carboxylic acids, aldehydes, alcohols, ethers, ketones, esters, and oligomeric lignin [12-14].

Anhydrosugars are important platform molecules for the synthesis of pharmaceuticals, petrochemicals, polymers, and plastics. It is widely accepted that fast pyrolysis of pure cellulose can get a high yield of levoglucosan $[15,16]$. However, fast pyrolysis of raw lignocellulosic biomass typically generates a very low yield of levoglucosan when compared with the theoretical yield based on its cellulose content. Lignocellulosic biomass is mainly composed of cellulose, hemicellulose, and lignin $[17,18]$. In addition, it also contains moisture and minor amounts of extractives and ash. The complicated compositions of biomass intensely affect the production distribution from fast pyrolysis. Considerable studies have been focused on the effect of chemical structure and composition on the product distribution from fast pyrolysis of biomass and its components [19-22]. It is found that alkali and alkaline earth metals (AAEM) in the ash is the most powerful factor in determining the yields of anhydrosugars. The alkali and alkaline earth metals, especially $\mathrm{Na}, \mathrm{K}, \mathrm{Ca}$, and $\mathrm{Mg}$, can act as catalysts for accelerating pyranose ring fragmentation resulting in the decrease in the yields of anhydrosugars and the increase in the yields of low molecular compounds (e.g., aldehydes and ketones) [23-25].

To date, many methods for removing or passivating the AAEM in biomass have been reported for enhancing the production of anhydrosugars from fast pyrolysis of biomass. Mourant and coworkers demonstrated that the removal of AAEM present in mallee wood by water washing and acid washing did not cause obvious changes in the yields of bio-oil and bio-char from fast pyrolysis. However, the removal of AAEM can significantly improve the yield of anhydrosugars and reduce the yields of water and low molecular compounds [26]. Zheng and co-workers found that microwave treatment of corncobs in glycerol can effectively remove the AAEM in raw corncobs, thus significantly improving the yield of levoglucosan in subsequent fast pyrolysis [27]. Brown and Garcia-Perez demonstrated that the passivation of AAEM using mineral acid can significantly enhance the yield of levoglucosan from fast pyrolysis of biomass [28,29]. Sui and co-workers showed that fast pyrolysis of bagasse impregnated with sulfuric acid or phosphoric acid at low temperature favored the formation of levoglucosenone [30]. Blasi suggested that $\mathrm{H}_{2} \mathrm{SO}_{4}$ can catalyze the selective pyrolysis of corncobs into furfural. However, there is still a lack of in-depth insight into the functions of $\mathrm{H}_{2} \mathrm{SO}_{4}$ during fast pyrolysis of acid-impregnated biomass. Hence, in this study, the effects of different $\mathrm{H}_{2} \mathrm{SO}_{4}$ concentrations on the product distributions from fast pyrolysis of $\mathrm{H}_{2} \mathrm{SO}_{4}$-impregnated eucalyptus were systematically investigated, especially the variation trends of anhydrosugars, furans phenols, carboxylic acids, aldehydes, and ketones. The functions of $\mathrm{H}_{2} \mathrm{SO}_{4}$ during fast pyrolysis were further explored by comparing the production distribution from fast pyrolysis of cellulose mixed with $\mathrm{H}_{2} \mathrm{SO}_{4}$ and ash derived from $\mathrm{H}_{2} \mathrm{SO}_{4}$-impregnated eucalyptus.

\section{Results and Discussion}

\subsection{X-Ray Fluorescence Spectroscopy (XRF) and XRD Analysis of Ash from Raw and $\mathrm{H}_{2} \mathrm{SO}_{4^{-}}$ Impregnated Eucalyptus}

The contents of selected elements in the ash were determined by XRF. As shown in Table 1, potassium $(\mathrm{K})$, calcium $(\mathrm{Ca})$, Sodium $(\mathrm{Na})$, magnesium $(\mathrm{Mg})$, sulfur $(\mathrm{S})$, and chlorine $(\mathrm{Cl})$ are the 
major elements in the two ashes. The ash from $0.5 \% \mathrm{H}_{2} \mathrm{SO}_{4}$-impregnated eucalyptus has a very high $\mathrm{S}$ content of $15.02 \mathrm{wt} \%$ and a relative low $\mathrm{Cl}$ content of $0.40 \mathrm{wt} \%$, while the other ashes exhibited opposite trends, indicating that the thermally stable sulfur-containing compounds were formed, and the chlorine-containing compounds were evaporated during pyrolysis of $0.5 \% \mathrm{H}_{2} \mathrm{SO}_{4}$-impregnated eucalyptus. After $\mathrm{H}_{2} \mathrm{SO}_{4}$ impregnation and washing, the contents of $\mathrm{AAEM}(\mathrm{K}, \mathrm{Ca}, \mathrm{Na}$, and $\mathrm{Mg}$, ) in ash were slightly reduced due to the effect of washing by solutions and the dilution by $\mathrm{S}$.

Table 1. Elemental analysis of ash.

\begin{tabular}{ccc}
\hline \multirow{2}{*}{ Element } & \multicolumn{2}{c}{ Elemental Analysis (wt $\%)$} \\
\cline { 2 - 3 } & $\mathbf{A}$ & $\mathbf{S A}$ \\
\hline $\mathrm{K}$ & 21.20 & 18.60 \\
$\mathrm{Ca}$ & 13.64 & 9.50 \\
$\mathrm{Na}$ & 5.61 & 5.11 \\
$\mathrm{Mg}$ & 3.30 & 3.22 \\
$\mathrm{Mn}$ & 1.70 & 1.44 \\
$\mathrm{Fe}$ & 1.42 & 1.62 \\
$\mathrm{P}$ & 1.31 & 1.29 \\
$\mathrm{~S}$ & 0.77 & 15.02 \\
$\mathrm{Cl}$ & 4.09 & 0.40
\end{tabular}

A: Ash from raw eucalyptus. SA: Ash from $0.5 \mathrm{wt} \% \mathrm{H}_{2} \mathrm{SO}_{4}$-impregnated eucalyptus.

The XRD patterns of the two ashes are shown in Figure 1. The diffraction peaks found at $2 \theta=28.4^{\circ}$, $40.6^{\circ}, 50.3^{\circ}, 58.8^{\circ}, 66.5^{\circ}$, and $73.9^{\circ}$ in ash from raw eucalyptus corresponded to the (200), (220), (222), (400), and (422) crystal planes of $\mathrm{KCl}$ (JCPDS 41-1476). It is worthy of noting that the ash from $0.5 \mathrm{wt} \%$ $\mathrm{H}_{2} \mathrm{SO}_{4}$-impregnated eucalyptus showed a very different diffraction pattern. Its diffraction peaks were well matched with the standard JCPDS 74-0398 for $\mathrm{K}_{3} \mathrm{Na}\left(\mathrm{SO}_{4}\right)_{2}$. The results demonstrated that $\mathrm{K}$ was predominantly in the form of $\mathrm{KCl}$ and $\mathrm{K}_{3} \mathrm{Na}\left(\mathrm{SO}_{4}\right)_{2}$ in the ashes from raw and $0.5 \% \mathrm{H}_{2} \mathrm{SO}_{4}$-impregnated eucalyptus, respectively. It was consistent with the result of XRF.

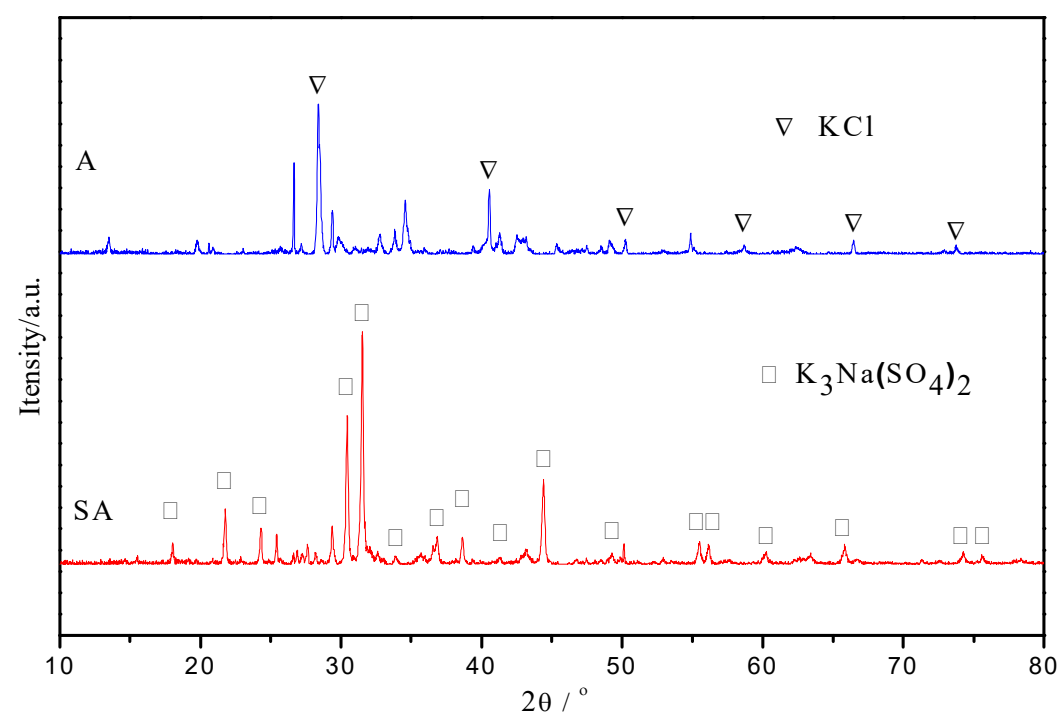

Figure 1. XRD patterns of the two ashes. A: Ash from raw eucalyptus. SA: Ash from $0.5 \mathrm{wt} \%$ $\mathrm{H}_{2} \mathrm{SO}_{4}$-impregnated eucalyptus.

2.2. Thermogravimetric Analysis of Raw and $\mathrm{H}_{2} \mathrm{SO}_{4}$-Impregnated Eucalyptus

The pyrolysis behaviors of raw and $\mathrm{H}_{2} \mathrm{SO}_{4}$-impregnated eucalyptus are examined by thermogravimetric analysis. The thermogravimetric (TG)/differential thermal gravity (DTG) curves of raw and $\mathrm{H}_{2} \mathrm{SO}_{4}$-impregnated eucalyptus are given in Figure 2, and their corresponding characteristic 
parameters are presented in Table 1 . The DTG curve shows a small shoulder at approximately $285^{\circ} \mathrm{C}$, which could be mainly described as the degradation of hemicellulose. The sharp peak that appears at a higher temperature is probably due to the thermal decomposition of cellulose [31]. As the $\mathrm{H}_{2} \mathrm{SO}_{4}$ concentrations increased, the maximum weight loss rates $\left(D_{\max }\right)$ first changed slightly and then gradually decreased. At the same time, the peak temperature $\left(T_{\max }\right)$ corresponding to the maximum weight loss rate shifted toward lower temperature. It is well accepted that AAEM could effectively catalyze the pyrolysis of cellulose, thus lowering the activation energy and improving the reaction rate. After $\mathrm{H}_{2} \mathrm{SO}_{4}$ impregnation, AAEM could react with $\mathrm{H}_{2} \mathrm{SO}_{4}$ to form thermally stable compounds without catalytic ability, resulting in the reduction in the weight loss rate and its peak temperature. The results indicated that $\mathrm{H}_{2} \mathrm{SO}_{4}$ could act as an inhibitor to suppress the catalytic activity of AAEM during pyrolysis of $\mathrm{H}_{2} \mathrm{SO}_{4}$-impregnated eucalyptus. As shown in Table 2, the rank order of char yield was $\mathrm{HCl}$-washed eucalyptus $<\mathrm{H}_{2} \mathrm{SO}_{4}$-impregnated eucalyptus $<$ raw eucalyptus. $\mathrm{HCl}$ washing could effectively remove the AAEM present in the raw eucalyptus. The char yield of $\mathrm{HCl}$-washed eucalyptus was evidently lower than those of raw and $\mathrm{H}_{2} \mathrm{SO}_{4}$-impregnated eucalyptus, indicating that AAEM played key roles in the formation of char during pyrolysis of eucalyptus. $\mathrm{H}_{2} \mathrm{SO}_{4}$ could act as an inhibitor to suppress the catalytic functions of AAEM. The results suggested that AAEM could simultaneously catalyze the pyranose ring-opening reactions and the char formation reactions during pyrolysis of biomass. Both the removal and passivation of AAEM could reduce the formation of char [32].

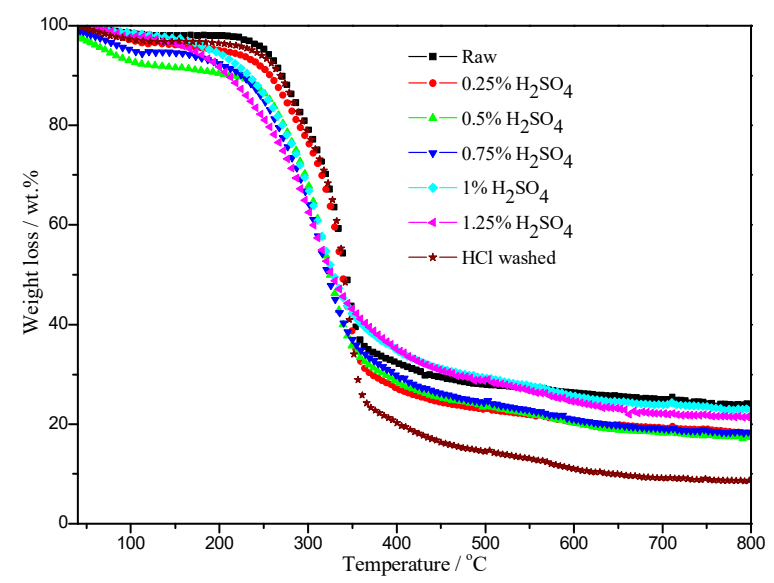

(a)

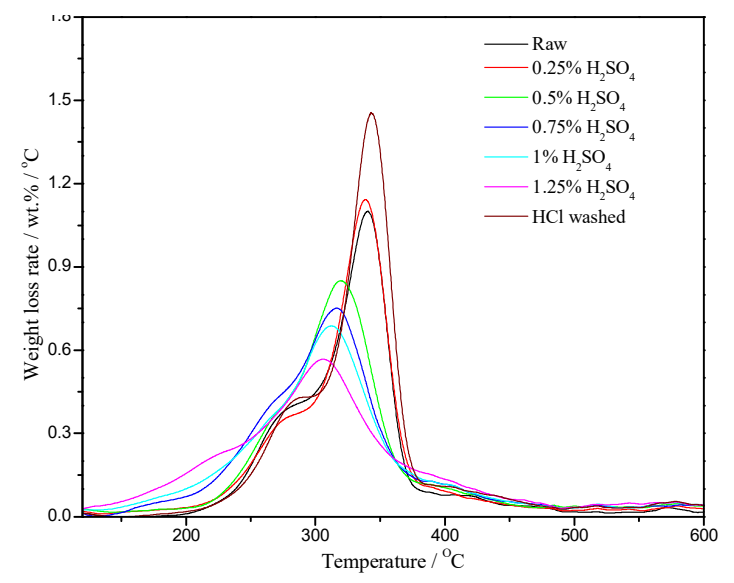

(b)

Figure 2. Thermogravimetric (TG) and differential thermal gravity (DTG) analysis of raw and $\mathrm{H}_{2} \mathrm{SO}_{4}$-impregnated eucalyptus: (a) TG curves of raw and $\mathrm{H}_{2} \mathrm{SO}_{4}$-impregnated eucalyptus, (b) DTG curves of raw and $\mathrm{H}_{2} \mathrm{SO}_{4}$-impregnated eucalyptus. 
Table 2. The pyrolysis characteristic parameters of raw and $\mathrm{H}_{2} \mathrm{SO}_{4}$-impregnated eucalyptus.

\begin{tabular}{cccc}
\hline Feedstocks & Char Yield (at $\left.\mathbf{8 0 0}{ }^{\circ} \mathbf{C}, \mathbf{w t} \%\right)$ & $\mathbf{T}_{\max }\left({ }^{\circ} \mathbf{C}\right)$ & $\mathbf{D}_{\max }\left(\mathbf{w t} \% /{ }^{\circ} \mathbf{C}\right)$ \\
\hline raw & 23.81 & 340.3 & 1.10 \\
$0.25 \% \mathrm{H}_{2} \mathrm{SO}_{4}$ & 15.16 & 338.6 & 1.14 \\
$0.5 \% \mathrm{H}_{2} \mathrm{SO}_{4}$ & 17.31 & 319.7 & 0.85 \\
$0.75 \% \mathrm{H}_{2} \mathrm{SO}_{4}$ & 18.24 & 316.7 & 0.75 \\
$1 \% \mathrm{H}_{2} \mathrm{SO}_{4}$ & 22.83 & 312.1 & 0.69 \\
$1.25 \% \mathrm{H}_{2} \mathrm{SO}_{4}$ & 18.21 & 305.7 & 0.57 \\
Demineralized & 8.54 & 343.2 & 1.46 \\
\hline me corresponding temperature of the maximum weight loss rate. $\mathrm{D}_{\max }$ : the maximum weight loss rate.
\end{tabular}

\subsection{Product Distributions from Fast Pyrolysis of Raw and $\mathrm{H}_{2} \mathrm{SO}_{4}$-Impregnated Eucalyptus}

The product distributions from fast pyrolysis of raw and $\mathrm{H}_{2} \mathrm{SO}_{4}$-impregnated eucalyptus are presented in Table 3. The identified compounds were classified into six groups according their main function groups: aldehydes, ketones, furans, phenols, acids, and anhydrosugars. It is evident that the product distributions from fast pyrolysis of eucalyptus were drastically altered by $\mathrm{H}_{2} \mathrm{SO}_{4}$ impregnation. As shown in Table 3, the contents of anhydrosugars, furans, and phenols were significantly improved by $\mathrm{H}_{2} \mathrm{SO}_{4}$-impregnation, whereas the contents of acids, aldehydes, and ketones was obviously reduced by $\mathrm{H}_{2} \mathrm{SO}_{4}$ impregnation. Hydroxy acetaldehyde and 1-hydroxy-2-propanone are typically considered as the products from ring-opening reactions of hemicellulose and cellulose via AAEM catalyzed retro-aldol condensation. Their contents were obviously reduced by $\mathrm{H}_{2} \mathrm{SO}_{4}$ impregnation. Additionally, their lowest contents were achieved at the $\mathrm{H}_{2} \mathrm{SO}_{4}$ concentrations of $1.25 \%$. The results demonstrated that $\mathrm{H}_{2} \mathrm{SO}_{4}$ can serve as an inhibitor to suppress AAEM catalyzed retro-aldol condensation during fast pyrolysis of eucalyptus, thus reducing the yields of low molecular compounds, such as hydroxy acetaldehyde and 1-hydroxy-2-propanone. Furfural, levoglucosan, and levoglucosenone, are the most representative and commercially valuable products from fast pyrolysis of cellulose and hemicellulose. Furfural is usually produced from acid-catalyzed dehydration of hemicellulose. The content of furfural from eucalyptus was promoted by $\mathrm{H}_{2} \mathrm{SO}_{4}$ impregnation. The content of furfural increased from $1.90 \%$ to $2.83 \%$ when the $0.25 \% \mathrm{H}_{2} \mathrm{SO}_{4}$ was impregnated with raw eucalyptus. As the $\mathrm{H}_{2} \mathrm{SO}_{4}$ concentration increased from $1.0 \%$ to $1.25 \%$, the content of furfural was sharply raised from $2.74 \%$ to $6.83 \%$, indicating that $\mathrm{H}_{2} \mathrm{SO}_{4}$ mainly acted as a catalyst for accelerating the dehydration reaction when $\mathrm{H}_{2} \mathrm{SO}_{4}$ concentration was greater than $1.0 \%$. The content of levoglucosan was sharply enhanced by $\mathrm{H}_{2} \mathrm{SO}_{4}$ impregnation. As the $\mathrm{H}_{2} \mathrm{SO}_{4}$ concentration increased from $0 \%$ to $0.25 \%$, the content of levoglucosan increased from $9.88 \%$ to $43.2 \%$ and reached the maximum value. As the $\mathrm{H}_{2} \mathrm{SO}_{4}$ concentration further increased from $0.5 \%$ to $1.25 \%$, the content of levoglucosan gradually declined from $43.2 \%$ to $27.95 \%$. It is speculated that $\mathrm{H}_{2} \mathrm{SO}_{4}$ first served as an inhibitor to suppress the catalytic functions of AAEM, resulting in the sharp increase in the content of levoglucosan. $\mathrm{H}_{2} \mathrm{SO}_{4}$ then acted as a catalyst for accelerating the formation of dehydrated product, leading to the enhancement in the contents of furfural and levoglucosenone and the decrease in the content of levoglucosan. The variation trend of levoglucosenone with different $\mathrm{H}_{2} \mathrm{SO}_{4}$ concentration strongly supported this speculation. Levoglucosenone is mainly generated by acid-catalyzed dehydration of levoglucosan. As shown in Table 4, the content of levoglucosenone is very low from fast pyrolysis of raw eucalyptus. Its content was also evidently improved by $\mathrm{H}_{2} \mathrm{SO}_{4}$ impregnation and reached the highest value of $2.38 \%$ at the $\mathrm{H}_{2} \mathrm{SO}_{4}$ concentration of $1.25 \%$. Acetic acid is predominantly formed from pyrolysis of hemicellulose, particularly from the O-acetylxylan and 4-O-methylglucuronic acid units [33]. The content of acetic acid was reduced by $\mathrm{H}_{2} \mathrm{SO}_{4}$ impregnation. Phenols are mainly derived from pyrolysis of lignin. The $\mathrm{H}_{2} \mathrm{SO}_{4}$-impregnated eucalyptus produced more phenols than the raw eucalyptus, especially 2-methoxy-4-vinylphenol (MVP) and 2-methoxy-4-(1-propenyl)-phenol (MPP). As the concentration of $\mathrm{H}_{2} \mathrm{SO}_{4}$ increased, the content of MVP and MPP first increased and then dropped. The results could be 
due to that both AAEM and excess $\mathrm{H}_{2} \mathrm{SO}_{4}$ could catalyze the polycondensation of lignin to form more char and less phenols.

Table 3. The product distributions from fast pyrolysis of raw and $\mathrm{H}_{2} \mathrm{SO}_{4}$-impregnated eucalyptus.

\begin{tabular}{|c|c|c|c|c|c|c|c|}
\hline \multirow{3}{*}{$\begin{array}{l}\text { Time } \\
\text { (min) }\end{array}$} & \multirow{3}{*}{ Compounds } & \multirow{3}{*}{ Raw } & \multicolumn{5}{|c|}{ Content $\mathrm{a} / \%$} \\
\hline & & & \multicolumn{5}{|c|}{$\mathrm{H}_{2} \mathrm{SO}_{4}$ Concentration (wt $\%$ ) } \\
\hline & & & 0.25 & 0.5 & 0.75 & 1 & 1.25 \\
\hline 4.762 & Acetaldehyde & 2.11 & 1.49 & 1.16 & 1.38 & 1.32 & 1.12 \\
\hline 8.306 & Acetaldehyde, hydroxy- & 2.82 & 0.84 & 0.98 & 0.55 & 0.59 & 0.3 \\
\hline 37.615 & 4-Methyl-2,5-dimethoxybenzaldehyde & 2.85 & 0.93 & 1.1 & 0.74 & 0.85 & 0.48 \\
\hline 41.216 & Benzaldehyde,4-hydroxy-3,5-dimethoxy- & 1.53 & 0.67 & 0.71 & 0.54 & 0.62 & 0.48 \\
\hline \multirow[t]{2}{*}{42.629} & $\begin{array}{l}\text { Ethanone, } \\
\text { 1-(4-hydroxy-3,5-dimethoxyphenyl)- }\end{array}$ & 0.89 & 0.7 & 0.8 & 0.69 & 0.68 & 0.72 \\
\hline & Total of aldehydes & 10.19 & 4.63 & 4.76 & 3.89 & 4.07 & 3.10 \\
\hline 5.657 & Acetone & 0.58 & 0.42 & 0.29 & 0.39 & 0.38 & 0.48 \\
\hline 7.146 & Methyl vinyl ketone & 0.29 & 0.28 & 0.15 & 0.23 & 0.2 & 0.31 \\
\hline 7.212 & 2,3-Butanedione & 0.75 & 0.44 & 0.34 & 0.38 & 0.35 & 0.32 \\
\hline 10.568 & 2-Propanone, 1-hydroxy- & 3.72 & 0.94 & 0.74 & 0.61 & 0.68 & 0.58 \\
\hline 13.819 & 1-Hydroxy-2-butanone & 0.41 & 0.55 & 0.07 & 0.35 & 0.5 & 0.15 \\
\hline 19.587 & 2-Cyclopenten-1-one, 2-hydroxy- & 1.5 & 0.59 & 0.54 & 0.45 & 0.45 & 0.48 \\
\hline 22.668 & 1,2-Cyclopentanedione, 3-methyl- & 1.28 & 0.58 & 0.55 & 0.51 & 0.51 & 0.52 \\
\hline \multirow[t]{2}{*}{26.953} & Levoglucosenone & 0.05 & 0.25 & 0.31 & 1.16 & 0.8 & 2.38 \\
\hline & Total of ketones & 8.58 & 4.04 & 2.99 & 4.07 & 3.87 & 5.22 \\
\hline 15.939 & Furfural & 1.9 & 2.83 & 2.21 & 3.07 & 2.74 & 6.83 \\
\hline 17.334 & 2-Furanmethanol & 0.38 & 0.21 & 0.21 & 0.22 & 0.25 & 0.28 \\
\hline 20.435 & 2-Furancarboxaldehyde, 5-methyl- & 0.27 & 0.36 & 0.36 & 0.33 & 0.29 & 0.55 \\
\hline 21.406 & 2(5H)-Furanone & 0.6 & 0.21 & 0.19 & 0.16 & 0.18 & 0.18 \\
\hline \multirow[t]{2}{*}{31.857} & 5-Hydroxymethylfurfural & 0.46 & 0.81 & 0.76 & 0.59 & 0.63 & 0.56 \\
\hline & Total of furans & 3.61 & 4.43 & 3.73 & 4.36 & 4.10 & 8.40 \\
\hline 23.498 & Phenol & 0.46 & 0.35 & 0.26 & 0.32 & 0.35 & 0.38 \\
\hline 24.129 & Phenol, 2-methoxy- & 0.78 & 0.5 & 0.64 & 0.49 & 0.6 & 0.7 \\
\hline 27.07 & Creosol & 0.41 & 0.32 & 0.36 & 0.3 & 0.42 & 0.41 \\
\hline 30.886 & 2-Methoxy-4-vinylphenol & 1.46 & 2.62 & 3.02 & 3.49 & 3.72 & 2.46 \\
\hline 31.508 & Phenol, 2-methoxy-3-(2-propenyl)- & 0.27 & 0.12 & 0.11 & 0.11 & 0.1 & 0.2 \\
\hline 32.253 & Phenol, 2,6-dimethoxy- & 2.31 & 1.23 & 1.36 & 1.16 & 1.43 & 1.6 \\
\hline 34.204 & Phenol, 2-methoxy-4-(1-propenyl)- & 1.4 & 2.2 & 2.55 & 2.34 & 2.48 & 1.71 \\
\hline \multirow[t]{2}{*}{39.17} & (E)-2,6-Dimethoxy-4-(propenyl)phenol & 0.55 & 0.15 & 0.17 & 0.15 & 0.16 & 0.21 \\
\hline & Total of phenols & 7.65 & 7.59 & 8.47 & 8.36 & 9.27 & 7.77 \\
\hline \multirow[t]{2}{*}{9.323} & Acetic acid & 7.42 & 4.17 & 3.44 & 3.38 & 3.57 & 4.07 \\
\hline & Total of acids & 7.42 & 4.17 & 3.44 & 3.38 & 3.57 & 4.07 \\
\hline 40.179 & levoglucosan & 9.88 & 40.14 & 43.2 & 41.33 & 38.93 & 27.95 \\
\hline \multirow[t]{2}{*}{43.45} & 1,6-Anhydro- $\beta$-D-glucofuranose (AGF) & 1.05 & 5.09 & 4.98 & 5.27 & 5.62 & 5.89 \\
\hline & Total of anhydrosugars & 11.85 & 49.31 & 53.57 & 53.58 & 50.02 & 37.63 \\
\hline
\end{tabular}

${ }^{\mathrm{a}}$ : The relative chromatographic area.

The yields of levoglucosan and 1,6-Anhydro- $\beta$-D-glucofuranose (AGF) from fast pyrolysis of raw and $\mathrm{H}_{2} \mathrm{SO}_{4}$-impregnated eucalyptus are illustrated in Figure 3. The yield of levoglucosan was $3.6 \%$ from fast pyrolysis of raw eucalyptus. It was found that even small amounts of $\mathrm{H}_{2} \mathrm{SO}_{4}$ can drastically improve the yield of levoglucosan due to the low content of inherent AAEM in raw eucalyptus. The yields of levoglucosan from $0.25 \% \mathrm{H}_{2} \mathrm{SO}_{4}$-impregnated eucalyptus were $17.8 \%$. The maximum yield of levoglucosan $(21.3 \%)$ was achieved by fast pyrolysis of $0.5 \% \mathrm{H}_{2} \mathrm{SO}_{4}$-impregnated eucalyptus. The value was close to its theoretical yield based on the cellulose content. As the $\mathrm{H}_{2} \mathrm{SO}_{4}$ concentration further increased from $0.5 \%$ to $1.25 \%$, the yield of levoglucosan decreased from $21.3 \%$ to $9.8 \%$. The results also supported that $\mathrm{H}_{2} \mathrm{SO}_{4}$ mainly served as an inhibitor to suppress the catalytic functions of AAEM when the $\mathrm{H}_{2} \mathrm{SO}_{4}$ concentration was less than or equal to $0.5 \%$. The excess $\mathrm{H}_{2} \mathrm{SO}_{4}$ then 
served as a catalyst for accelerating the dehydration reaction, resulting in the decrease in the yield of levoglucosan. Similarly, the yield of AGF was enhanced by $\mathrm{H}_{2} \mathrm{SO}_{4}$ impregnation. However, the concentration of $\mathrm{H}_{2} \mathrm{SO}_{4}$ did not exert significant impacts on the yield of AGF. Demineralization of eucalyptus by $\mathrm{HCl}$ washing can effectively promote the yield of levoglucosan. It is worthy of note that the yield of levoglucosan from $\mathrm{HCl}$-washed eucalyptus was evidently lower than that from $0.5 \%$ $\mathrm{H}_{2} \mathrm{SO}_{4}$-impregnated eucalyptus. It could be attributed to that the AAEM in eucalyptus cannot be totally removed by $\mathrm{HCl}$ washing.

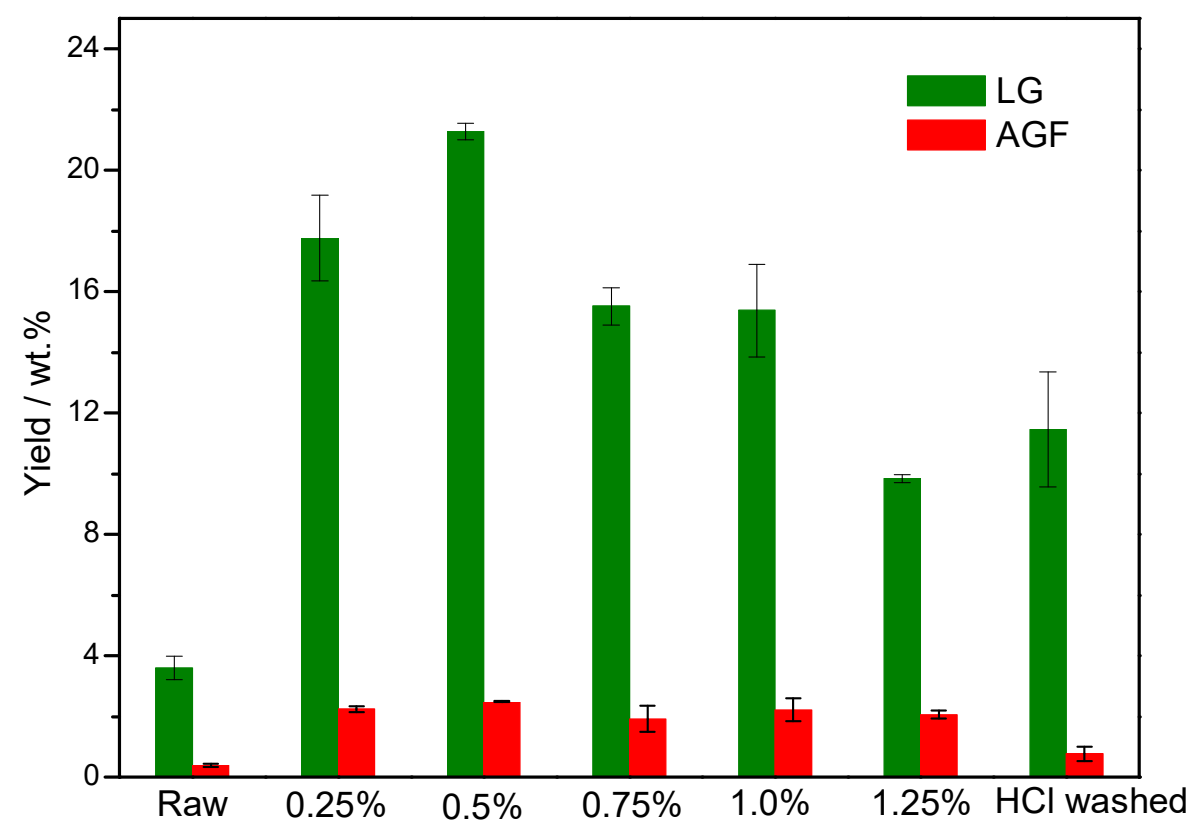

Figure 3. The yields of levoglucosan (LG) and AGF from fast pyrolysis of raw and $\mathrm{H}_{2} \mathrm{SO}_{4}$ impregnated eucalyptus.

\subsection{The Possible Roles of $\mathrm{H}_{2} \mathrm{SO}_{4}$ during Fast Pyrolysis of $\mathrm{H}_{2} \mathrm{SO}_{4}$-Impregnated Eucalyptus}

In order to further reveal the possible roles of $\mathrm{H}_{2} \mathrm{SO}_{4}$ during fast pyrolysis, the yield of levoglucosan from cellulose mixed with $\mathrm{H}_{2} \mathrm{SO}_{4}$ and ash is graphed in Figure 4. It is obvious that the addition of $\mathrm{H}_{2} \mathrm{SO}_{4}, \mathrm{~K}_{2} \mathrm{SO}_{4}$, and ash from $0.5 \% \mathrm{H}_{2} \mathrm{SO}_{4}$-impregnated eucalyptus can cause the significant decrease in the yield of levoglucosan from fast pyrolysis of cellulose, indicating that the presence of AAEM in the form of metal sulfate (e.g., $\mathrm{K}_{3} \mathrm{Na}\left(\mathrm{SO}_{4}\right)_{2}$ or $\mathrm{K}_{2} \mathrm{SO}_{4}$ ) was not the decisive reason for the increase in the yield of levoglucosan from fast pyrolysis of $\mathrm{H}_{2} \mathrm{SO}_{4}$-impregnated eucalyptus. $\mathrm{H}_{2} \mathrm{SO}_{4}$ could react with the AAEM and organic macromolecules in eucalyptus to form a metal-organic complex. Shafizadeh found that water washing combined with $\mathrm{H}_{2} \mathrm{SO}_{4}$ impregnation was capable of maximizing the yield of anhydrosugars only when lignin was present [34]. Hence, it is speculated that $\mathrm{H}_{2} \mathrm{SO}_{4}$ first reacted with AAEM and lignin to form lignosulfonates (e.g., potassium lignosulfonate, calcium lignosulfonate.), resulting in the effective reduction in the catalytic functions of AAEM during fast pyrolysis of $\mathrm{H}_{2} \mathrm{SO}_{4}$-impregnated eucalyptus. 


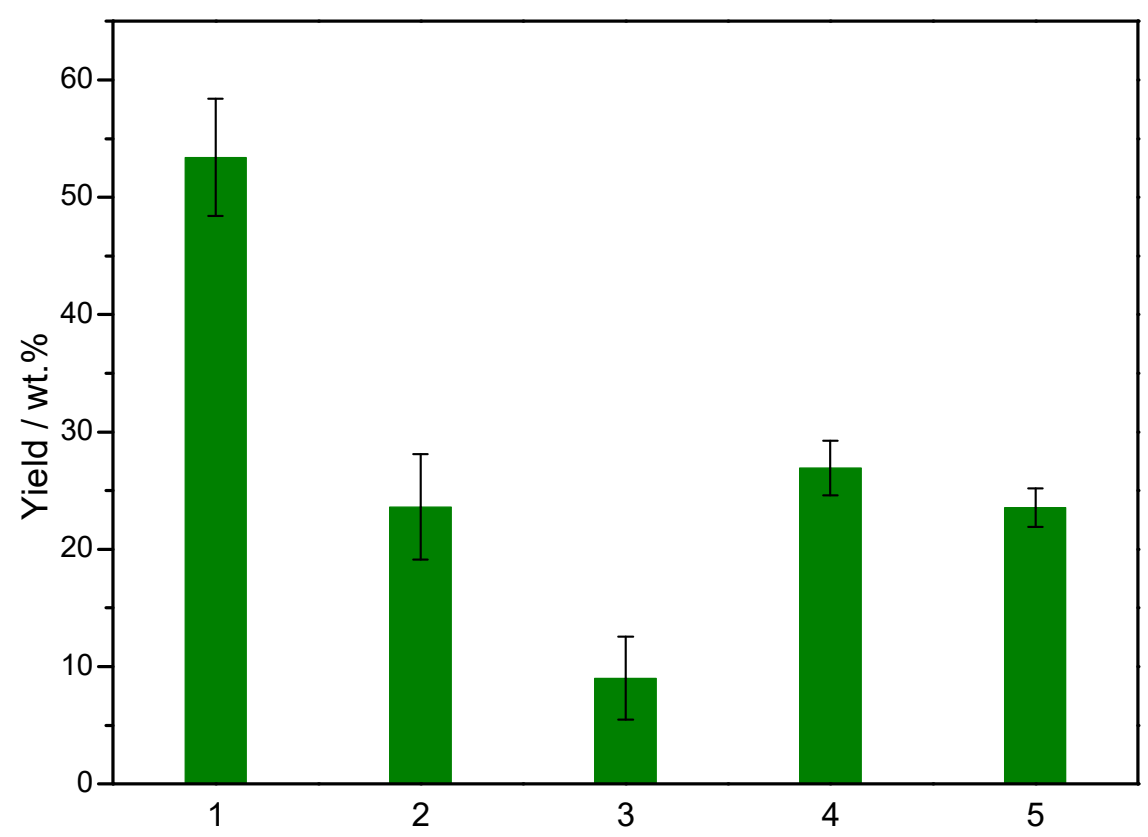

Figure 4. The yield of levoglucosan from fast pyrolysis of cellulose mixed with $\mathrm{H}_{2} \mathrm{SO}_{4}$ and ash. (1: pure cellulose, 2: cellulose impregnated with $0.5 \% \mathrm{H}_{2} \mathrm{SO}_{4}$, 3: cellulose impregnated with $0.5 \% \mathrm{~K}_{2} \mathrm{SO}_{4}, 4$ : cellulose mixed with $\mathrm{SA}, 5$ : cellulose mixed with A).

\section{Experimental}

\subsection{Materials}

Eucalyptus used in this study was acquired from a local wood processing factory in Guangzhou, China. Before the experiment, the samples were ground and sieved to a particle size of 60-80 mesh, and then dried at $105^{\circ} \mathrm{C}$ for $12 \mathrm{~h}$. The elemental analysis of eucalyptus is listed in Table 4. Sulfuric acid (analytical grade, 98\%) was purchased from Guangzhou Chemical Reagent Factory, Guangzhou, China. Pure cellulose was obtained from Fuyu Fine Chemical, Tianjin, China.

Table 4. Elemental analysis of raw and acid-impregnated eucalyptus.

\begin{tabular}{|c|c|c|c|c|c|c|c|c|}
\hline \multirow{2}{*}{ Items } & \multicolumn{8}{|c|}{ Elemental Analysis (wt\%) ${ }^{a}$} \\
\hline & C & $\mathbf{H}$ & $\mathbf{N}$ & $\mathbf{S}$ & $\mathbf{O}^{b}$ & Ash & $\mathrm{H} / \mathrm{C}^{\mathrm{c}}$ & $O / C^{d}$ \\
\hline Raw & 48.10 & 5.96 & 0.13 & 0.06 & 45.37 & 0.38 & 0.12 & 0.94 \\
\hline $0.5 \% \mathrm{H}_{2} \mathrm{SO}_{4}$ & 47.30 & 5.74 & 0.09 & 0.17 & 46.26 & 0.44 & 0.12 & 0.98 \\
\hline
\end{tabular}

\section{2. $\mathrm{H}_{2} \mathrm{SO}_{4}$ Impregnation of Eucalyptus}

The eucalyptus ( $10 \mathrm{~g}$ ) was impregnated with $50 \mathrm{~mL} \mathrm{H}_{2} \mathrm{SO}_{4}$ solutions with various concentrations $(0.25 \mathrm{wt} \%, 0.5 \mathrm{wt} \%, 0.75 \mathrm{wt} \%, 1.0 \mathrm{wt} \%$, and $1.25 \mathrm{wt} \%$ based on the dry weight of eucalyptus) in a beaker and then the beaker was put under ultrasonic irradiation for $3 \mathrm{~h}$ at room temperature. The $\mathrm{H}_{2} \mathrm{SO}_{4}$-impregnated eucalyptus was then dried at $80^{\circ} \mathrm{C}$ for $24 \mathrm{~h}$.

\subsection{Demineralization of Eucalyptus}

The eucalyptus $(10 \mathrm{~g})$ was washed with $100 \mathrm{~mL}$ of $2.0 \mathrm{M} \mathrm{HCl}$ solution at room temperature with stirring for $24 \mathrm{~h}$ to realize demineralization and then filtered to neutral-denoted as demineralized eucalyptus. The eucalyptus $(10 \mathrm{~g})$ was washed with $100 \mathrm{~mL}$ deionized water with stirring for $24 \mathrm{~h}$ 
for the removal of extractable ash and then filtered-denoted as water-washed eucalyptus. All the samples were dried at $80^{\circ} \mathrm{C}$ for $24 \mathrm{~h}$ to remove moisture.

\subsection{Thermogravimetric Analysis}

Thermal degradation behaviors of raw and $\mathrm{H}_{2} \mathrm{SO}_{4}$-impregnated eucalyptus were studied in a thermogravimetric analyzer (STA PT 1600, Linseis, Germany). In each experiment, the samples (20 mg) were conducted at a heating rate of $10{ }^{\circ} \mathrm{C} / \mathrm{min}$ from 40 to $800{ }^{\circ} \mathrm{C}$, and high purity nitrogen $(99.99 \%)$ with a flow rate of $100 \mathrm{~mL} / \mathrm{min}$ was used as the purge gas.

\subsection{Fast Pyrolysis of Raw and $\mathrm{H}_{2} \mathrm{SO}_{4}$-Impregnated Eucalyptus}

Fast pyrolysis of raw and $\mathrm{H}_{2} \mathrm{SO}_{4}$-impregnated eucalyptus was conducted on a pyroprobe reactor (Pyroprobe 5200 Series, CDS Analytical, Oxford, PA, USA) coupled with a gas chromatograph (7890A, Agilent Technologies, Santa Clara, CA, USA) connected with a mass spectrometer (5975C, Agilent Technologies, Santa Clara, CA, USA). In each experiment, a sample size of approximately $0.3 \sim 0.5 \mathrm{mg}$ was weighed using an electronic balance with an accuracy of $0.001 \mathrm{mg}$ (XP6152, METTLER TOLEDO, Germany). The temperature, heating rate, and residence time of pyrolysis were $600{ }^{\circ} \mathrm{C}, 10{ }^{\circ} \mathrm{C} / \mathrm{ms}$ and $20 \mathrm{~s}$, respectively. The compounds were identified by comparison with the national institute of standards and technology (NIST) mass spectral data library. Quantitative analysis of main pyrolysis products was made using the external standard method. The yields of main pyrolysis products were calculated based on the dry weight of the solid sample used in the pyrolysis experiment.

\subsection{X-ray Diffractometer Analysis (XRD) and X-ray Fluorescence Analysis (XRF) of Ash}

The ash from the raw and $\mathrm{H}_{2} \mathrm{SO}_{4}$-impregnated eucalyptus was prepared in a muffle furnace at $600{ }^{\circ} \mathrm{C}$ for $40 \mathrm{~min}$ under an air atmosphere. The XRD patterns of ash were examined by X-ray diffraction (X'Pert Pro MPD, PANalytical B.V., Almelo, The Netherlands) using $\mathrm{Cu} K \alpha$ radiation $(\lambda=0.15406 \mathrm{~nm})$ at $40 \mathrm{kV}$ and $40 \mathrm{~mA}$. The samples were scanned at a scanning rate of $10^{\circ} / \mathrm{min}$ from $2 \theta=10^{\circ}$ to $80^{\circ}$ with a step of $0.1^{\circ}$. The contents of elements in the ash were analyzed by $\mathrm{X}$-ray fluorescence spectroscopy (AxiosmAX Petro, PANalytical B.V., Almelo, The Netherlands) spectrophotometer with $2.4 \mathrm{~kW} \mathrm{Rh}$ K $\alpha$ radiation.

\section{Conclusions}

It was demonstrated that $\mathrm{H}_{2} \mathrm{SO}_{4}$ impregnation is an effective method for the selective production of anhydrosugars from fast pyrolysis of eucalyptus. Even small amounts of $\mathrm{H}_{2} \mathrm{SO}_{4}(0.25-0.5 \%)$ can obviously improve the production of anhydrosugars and suppress the formation of carboxylic acids, aldehydes, and ketones from fast pyrolysis of eucalyptus. The maximum yield of levoglucosan $(21.3 \%)$ was achieved by fast pyrolysis of $0.5 \% \mathrm{H}_{2} \mathrm{SO}_{4}$-impregnated eucalyptus. The value was close to its theoretical yield based on the cellulose content. As the $\mathrm{H}_{2} \mathrm{SO}_{4}$ concentration was further increased from $0.5 \%$ to $1.25 \%$, the yield of levoglucosan decreased from $21.3 \%$ to $9.8 \%$. It is speculated that $\mathrm{H}_{2} \mathrm{SO}_{4}$ first reacted with AAEM and lignin to form lignosulfonates, which can serve as an inhibitor to suppress the catalytic functions of AAEM, resulting in the sharp increase in the production of levoglucosan. As the $\mathrm{H}_{2} \mathrm{SO}_{4}$ concentration further increased, the excess $\mathrm{H}_{2} \mathrm{SO}_{4}$ can act as a catalyst for accelerating the formation of dehydrated product, leading to the decrease in the production of levoglucosan and the enhancement in the production of furfural and levoglucosenone. These findings can provide better understanding and insights into the pyrolysis behaviors of $\mathrm{H}_{2} \mathrm{SO}_{4}$-impregnated woody biomass.

Author Contributions: Conceptualization, A.Z.; Formal analysis, D.Z.; Writing-Original Draft preparation: D.Z.; Writing-Review \& Editing: A.Z.; Investigation: D.Z. and Y.F.; Resources: H.L.; Project Administration, Z.Z.; Supervision: F.W. 
Funding: This work was supported by the Major International (Regional) Joint Research Project of the National Natural Science Foundation of China (grant number 51661145011), the National Natural Science Foundation of China (grant numbers 51776209), the Science and Technology Planning Project of Guangdong Province (grant number 2015A020215024), Youth Innovation Promotion Association of Chinese Academy of Sciences (2018383) and the Pearl River S\&T Nova Program of Guangzhou City (grant number 201806010061) for financial support of this work.

Conflicts of Interest: The authors declare no conflict of interest.

\section{References}

1. Wang, S.; Dai, G.; Yang, H.; Luo, Z. Lignocellulosic biomass pyrolysis mechanism: A state-of-the-art review. Prog. Energy Combust. Sci. 2017, 62, 33-86. [CrossRef]

2. Huber, G.W.; Iborra, S.; Corma, A. Synthesis of transportation fuels from biomass: Chemistry, catalysts, and engineering. Chem. Rev. 2006, 106, 4044-4098. [CrossRef] [PubMed]

3. Zhang, H.; Xiao, R.; Wang, D.; He, G.; Shao, S.; Zhang, J.; Zhong, Z. Biomass fast pyrolysis in a fluidized bed reactor under $\mathrm{N}_{2}, \mathrm{CO}_{2}, \mathrm{CO}, \mathrm{CH}_{4}$ and $\mathrm{H}_{2}$ atmospheres. Bioresour. Technol. 2011, 102, 4258-4264. [CrossRef] [PubMed]

4. Zeng, K.; Minh, D.P.; Gauthier, D.; Weiss-Hortala, E.; Nzihou, A.; Flamant, G. The effect of temperature and heating rate on char properties obtained from solar pyrolysis of beech wood. Bioresour. Technol. 2015, 182, 114-119. [CrossRef] [PubMed]

5. Shen, D.; Jin, W.; Hu, J.; Xiao, R.; Luo, K.J.R.; Reviews, S.E. An overview on fast pyrolysis of the main constituents in lignocellulosic biomass to valued-added chemicals: Structures, pathways and interactions. Renew. Sustain. Energy Rev. 2015, 51, 761-774. [CrossRef]

6. Roy, P.; Dias, G. Prospects for pyrolysis technologies in the bioenergy sector: A review. Renew. Sustain. Energy Rev. 2017, 77, 59-69. [CrossRef]

7. Zheng, A.; Zhao, Z.; Chang, S.; Huang, Z.; Wang, X.; He, F.; Li, H. Effect of torrefaction on structure and fast pyrolysis behavior of corncobs. Bioresour. Technol. 2013, 128, 370-377. [CrossRef] [PubMed]

8. Wright, M.M.; Daugaard, D.E.; Satrio, J.A.; Brown, R.C. Techno-economic analysis of biomass fast pyrolysis to transportation fuels. Fuel 2010, 89, S2-S10. [CrossRef]

9. Zhang, H.; Xiao, R.; Huang, H.; Xiao, G.J. Comparison of non-catalytic and catalytic fast pyrolysis of corncob in a fluidized bed reactor. Bioresour. Technol. 2009, 100, 1428-1434. [CrossRef]

10. Bridgwater, A.V. Review of fast pyrolysis of biomass and product upgrading. Biomass Bioenergy 2012, 38, 68-94. [CrossRef]

11. Cao, J.-P.; Li, L.-Y.; Morishita, K.; Xiao, X.-B.; Zhao, X.-Y.; Wei, X.-Y.; Takarada, T. Nitrogen transformations during fast pyrolysis of sewage sludge. Fuel 2013, 104, 1-6. [CrossRef]

12. Zhang, H.; Xiao, R.; Wang, D.; Zhong, Z.; Song, M.; Pan, Q.; He, G. Fuels, Catalytic fast pyrolysis of biomass in a fluidized bed with fresh and spent fluidized catalytic cracking (FCC) catalysts. Energy Fuels 2009, 23, 6199-6206. [CrossRef]

13. Lu, Q.; Li, W.-Z.; Zhu, X.-F. Overview of fuel properties of biomass fast pyrolysis oils. Convers. Manag. 2009, 50, 1376-1383. [CrossRef]

14. Czernik, S.; Bridgwater, A.V. Overview of applications of biomass fast pyrolysis oil. Energy Fuels 2004, 18, 590-598. [CrossRef]

15. Wang, S.; Guo, X.; Liang, T.; Zhou, Y.; Luo, Z. Mechanism research on cellulose pyrolysis by Py-GC/MS and subsequent density functional theory studies. Bioresour. Technol. 2012, 104, 722-728. [CrossRef] [PubMed]

16. Lu, Q.; Yang, X.-C.; Dong, C.-Q.; Zhang, Z.-F.; Zhang, X.-M.; Zhu, X.-F. Influence of pyrolysis temperature and time on the cellulose fast pyrolysis products: Analytical Py-GC/MS study. J. Anal. Appl. Pyrolysis 2011, 92, 430-438. [CrossRef]

17. Wang, S.; Guo, X.; Wang, K.; Luo, Z.; Pyrolysis, A. Influence of the interaction of components on the pyrolysis behavior of biomass. J. Anal. Appl. Pyrolysis 2011, 91, 183-189. [CrossRef]

18. Li, R.; Zeng, K.; Soria, J.; Mazza, G.; Gauthier, D.; Rodriguez, R.; Flamant, G. Product distribution from solar pyrolysis of agricultural and forestry biomass residues. Renew. Energy 2016, 89, 27-35. [CrossRef]

19. Eom, I.Y.; Kim, K.H.; Kim, J.Y.; Lee, S.M.; Yeo, H.M.; Choi, I.G.; Choi, J.W. Characterization of primary thermal degradation features of lignocellulosic biomass after removal of inorganic metals by diverse solvents. Bioresour. Technol. 2011, 102, 3437-3444. [CrossRef] 
20. Xing, S.; Yuan, H.; Huhetaoli; Qi, Y.; Lv, P.; Yuan, Z.; Chen, Y. Characterization of the decomposition behaviors of catalytic pyrolysis of wood using copper and potassium over thermogravimetric and Py-GC/MS analysis. Energy 2016, 114, 634-646. [CrossRef]

21. Marathe, P.S.; Oudenhoven, S.R.G.; Heerspink, P.W.; Kersten, S.R.A.; Westerhof, R.J.M. Fast pyrolysis of cellulose in vacuum: The effect of potassium salts on the primary reactions. Chem. Eng. J. 2017, 329, 187-197. [CrossRef]

22. Wiinikka, H.; Johansson, A.-C.; Sandström, L.; Öhrman, O.G. Fate of inorganic elements during fast pyrolysis of biomass in a cyclone reactor. Fuel 2017, 203, 537-547. [CrossRef]

23. Keown, D.M.; Favas, G.; Hayashi, J.; Li, C.Z. Volatilisation of alkali and alkaline earth metallic species during the pyrolysis of biomass: Differences between sugar cane bagasse and cane trash. Bioresour. Technol. 2005, 96, 1570-1577. [CrossRef] [PubMed]

24. Nowakowski, D.; Jones, J.; Brydson, R.; Ross, A. Potassium catalysis in the pyrolysis behaviour of short rotation willow coppice. Fuel 2007, 86, 2389-2402. [CrossRef]

25. Patwardhan, P.R.; Satrio, J.A.; Brown, R.C.; Shanks, B.H. Influence of inorganic salts on the primary pyrolysis products of cellulose. Bioresour. Technol. 2010, 101, 4646-4655. [CrossRef] [PubMed]

26. David, G.F.; Perez, V.H.; Rodriguez Justo, O.; Garcia-Perez, M. Effect of acid additives on sugarcane bagasse pyrolysis: Production of high yields of sugars. Bioresour. Technol. 2017, 223, 74-83. [CrossRef] [PubMed]

27. Zheng, A.; Zhao, Z.; Huang, Z.; Zhao, K.; Wei, G.; Jiang, L.; Wang, X.; He, F.; Li, H. Overcoming biomass recalcitrance for enhancing sugar production from fast pyrolysis of biomass by microwave pretreatment in glycerol. Green Chem. 2015, 17, 1167-1175. [CrossRef]

28. Dalluge, D.L.; Daugaard, T.; Johnston, P.; Kuzhiyil, N.; Wright, M.M.; Brown, R.C. Continuous production of sugars from pyrolysis of acid-infused lignocellulosic biomass. Green Chem. 2014, 16, 4144-4155. [CrossRef]

29. Zhou, S.; Mourant, D.; Lievens, C.; Wang, Y.; Li, C.-Z.; Garcia-Perez, M. Effect of sulfuric acid concentration on the yield and properties of the bio-oils obtained from the auger and fast pyrolysis of Douglas Fir. Fuel 2013, 104, 536-546. [CrossRef]

30. Sui, X.W.; Wang, Z.; Liao, B.; Zhang, Y.; Guo, Q.X. Preparation of levoglucosenone through sulfuric acid promoted pyrolysis of bagasse at low temperature. Bioresour. Technol. 2012, 103, 466-469. [CrossRef]

31. Zhang, S.; Dong, Q.; Zhang, L.; Xiong, Y. Effects of water washing and torrefaction on the pyrolysis behavior and kinetics of rice husk through TGA and Py-GC/MS. Bioresour. Technol. 2016, 199, 352-361. [CrossRef] [PubMed]

32. Zhou, S.; Wang, Z.; Liaw, S.-S.; Li, C.-Z.; Garcia-Perez, M. Effect of sulfuric acid on the pyrolysis of Douglas fir and hybrid poplar wood: Py-GC/MS and TG studies. J. Anal. Appl. Pyrolysis 2013, 104, 117-130. [CrossRef]

33. Shen, D.K.; Gu, S.; Bridgwater, A.V. Study on the pyrolytic behaviour of xylan-based hemicellulose using TG-FTIR and Py-GC-FTIR. J. Anal. Appl. Pyrolysis 2010, 87, 199-206. [CrossRef]

34. Shafizadeh, F.; Stevenson, T.T. Saccharification of douglas-fir wood by a combination of prehydrolysis and pyrolysis. J. Appl. Polym. Sci. 2010, 27, 4577-4585. [CrossRef] 